\title{
On the solar cycle dependence of winds and planetary waves as seen from mid-latitude D1 LF mesopause region wind measurements*
}

\author{
C. Jacobi \\ Institute for Meteorology, University of Leipzig, Stephanstr. 3, D-04103 Leipzig, Germany \\ Fax: + 49341221 0937; e-mail: jacobi@rz.uni-leipzig.de
}

Received: 6 October 1997 / Received: 18 March 1998 / Accepted: 25 March 1998

\begin{abstract}
At the Collm Observatory of the University of Leipzig LF D1 low-frequency total reflection nighttime wind measurements have been carried out continuously for more than two decades. Using a multiple regression analysis to derive prevailing winds, tides and the quasi-2-day wave from the half-hourly mean values of the horizontal wind components, monthly mean values of mesopause wind parameters are obtained that can be analysed with respect to long-term trends and influences of solar variability. The response of the prevailing wind to the 11-year solar cycle differs throughout the year. While in winter no significant correlation between the zonal prevailing wind and solar activity is found, in spring and summer a negative correlation between the TWC can be seen from the measurements. This is connected with stronger vertical gradients of the zonal prevailing wind during solar maximum than during solar minimum. Since the amplitude of the quasi-2-day wave is dependent on the zonal mean wind vertical gradient, this is connected with a positive correlation between solar activity and quasitwo-day wave activity.
\end{abstract}

Key words. Meteorology and atmospheric dynamics · Middle atmosphere dynamics Multiple regression analysis Quasi-2-day wave

\section{Background}

One of the first investigations of the solar cycle dependence on the mesopause region winds was made

\footnotetext{
*Paper Presented at the Second IAGA/ICMA (IAMAS) Workshop on Solar Activity Forcing of the Middle Atmosphere, Prague, August 1997
}

by Sprenger and Schminder (1969). From low-frequency, closely spaced receiver LF D1 measurements at Kühlungsborn $\left(55^{\circ} \mathrm{N}\right)$ and Collm $\left(52^{\circ} \mathrm{N}\right)$, Germany, they found a strong positive correlation of both zonal and meridional (which is positive if directed towards the north) prevailing wind with solar activity in winter, and a decrease in the winter semidiurnal tidal amplitude with increasing solar flux. These results were confirmed by Portnyagin et al. (1977) using additional D1 data and also D2 (meteor radar) data from Obninsk, Russia. However, considering the zonal prevailing wind and the semidiurnal tidal amplitude, the solar cycle dependence as obtained from the D2 measurements was much weaker than the one found using the D1 measurements. Gregory et al. (1981) analysed mesospheric winds at Saskatoon, Canada, which were measured in 1978 and 1979 during high solar activity, and found differences compared with the CIRA 1972 model data, which were mostly obtained during years of low solar activity. They found a negative solar cycle dependence in some summer months as well as in February and March, while in December and February a positive solar cycle dependence was found, which coincided with the results of Sprenger and Schminder (1969).

Analyses of the Obninsk D2 long-term measurements were also presented by D'Yachenko et al. (1986), who pointed out that oscillations with a period of 11 years were present within the time series of the prevailing wind and the semidiurnal tidal amplitude. Another study was carried out by Dartt et al. (1983), who, using data from different stations at northern middle latitudes, qualitatively confirmed the results of Sprenger and Schminder (1969) concerning the solar cycle dependence of the winter prevailing wind. Additionally, they found a negative correlation of the spring and early summer zonal prevailing wind with the solar activity, and a positive correlation of the meridional prevailing wind with the solar activity from January through July. Greisiger et al. (1987), however, in contrast to the earlier results of Sprenger and Schminder (1969) or Portnyagin et al. (1977), found negative correlation of solar flux and 
zonal prevailing wind in winter as well as in summer, although they could confirm the negative correlation of solar flux and semidiurnal tide that was found by Sprenger and Schminder (1969) or Portnyagin et al. (1977). Since Greisiger et al. (1987) used D1 data from the same sites as Sprenger and Schminder (1969), this is a hint that the apparent solar cycle dependence of the prevailing wind in winter as established using the results of the earlier years was not a real solar effect, but rather a result of either measurement uncertainties or pure chance due to long-term variations in the winter mesopause region prevailing wind that are of non-solar origin. The latter explanation, however, seems to be more probable, since the apparent positive solar cycle dependence of the winter zonal prevailing wind in these years was found from winds measured at several northern mid-latitude sites at different longitudes (Sprenger and Schminder, 1969; Portnyagin et al., 1977; Gregory et al., 1981).

Namboothiri et al. (1993a) examined Saskatoon data from the period of 1979 through 1990. They found a positive correlation of the zonal prevailing wind with solar activity in winter, and a negative one in summer, thus confirming the results of Dartt et al. (1983), but not those of Greisiger et al. (1987) for winter. Using data from the southern hemisphere, Fraser (1990) pointed out that the results concerning a solar control of the prevailing wind and the semidiurnal tide are not conclusive.

Recently, Bremer et al. (1997) analysed more than 30 years of mesopause-region wind data. They reported positive correlation of the zonal as well as of the meridional wind with the solar flux in winter, and negative correlation in summer, although their results were not statistically significant. It has to be kept in mind that they also included some Collm and Kühlungsborn D1 data in their analysis, which had already been used in the studies of Portnyagin et al. (1977) and Greisiger et al. (1987). Using Collm data only, Jacobi et al. (1997a) found no solar cycle dependence of the semidiurnal tidal amplitude. This was already found by Fraser et al. (1989), in contradiction to the results of Sprenger and Schminder (1969) and Greisiger et al. (1987). As shown by Jacobi et al. (1997a), the time series of the semidiurnal tidal amplitude yields an oscillation with a period of more than 20 years which, however, does not coincide with any solar cycle and which is responsible for different results concerning an apparent solar cycle dependence detected from a time series shorter than about two decades [see also Jacobi et al. (1997b) their Fig. 7]. The positive solar cycle dependence of the winter zonal prevailing wind that was found by some authors could not be confirmed by Jacobi et al. (1997a), but a negative solar cycle dependence of the spring and summer zonal prevailing wind was reported.

Recently, Arnold and Robinson (1998) presented model results that showed a solar cycle effect on the winter mesospheric circulation which, however, decreases rapidly above $80 \mathrm{~km}$ altitude. This could be one of the reasons for the different results that were obtained in the past, and thus one may summarise that the results concerning a possible solar cycle effect on the winter mid-latitude mesopause region are not very conclusive and it is doubtful whether a measured effect on the region above the mesosphere really is of solar origin. However, as far as the summer zonal prevailing wind is concerned, a negative solar cycle dependence was found by most authors. With respect to the meridional prevailing wind it is also doubtful whether there is an 11-year solar cycle effect on the mid-latitude mesopause dynamics. Namboothiri et al. (1993a) found only a tendency towards such an influence, while the stronger winter southerly (or weaker northerly, respectively) winds that were found by Sprenger and Schminder (1969) during solar maximum could not be confirmed by measurements in later years. So Bremer et al. (1997) did not find a significant solar cycle dependence of the meridional prevailing wind in winter from Kühlungsborn D2 measurements, and this was confirmed by the results of Jacobi et al. (1997a,b) who used Collm D1 measurements, but from different years to those used by Sprenger and Schminder (1969).

One of the most prominent patterns in summer mesopause dynamics is the quasi-2-day wave known since the early 1970s (Muller, 1972; Babadshanov et al., 1973). Measurements and theoretical investigations have shown that this phenomenon generally occurs shortly after the summer solstice or reaches its maximum amplitude then. From many of the investigations it was found that the quasi-2-day wave is a westwardpropagating wave of zonal wavenumber 3 (Muller and Nelson, 1978; Rodgers and Prata, 1981). Recently, however, Poole and Harris (1995) obtained a wavenumber of less than 3 from simultaneous measurements at two southern hemisphere sites, while Meek et al. (1996) obtained zonal wavenumbers between 3 and 4 from phase comparisons using radar wind measurements in the northern hemisphere. Long-term studies of the quasi-2-day wave from measurements at single sites have been carried out by Harris (1994) and Jacobi et al. (1997c). The period of the quasi-2-day wave is often found to be slightly longer than $48 \mathrm{~h}$ (e.g. Muller and Nelson, 1978), but recent results have shown that during the maximum of the wave amplitude the period is smaller than $48 \mathrm{~h}$ (Thayaparan et al., 1997a,b; Jacobi et al., 1997c).

Two mechanisms of the development of the wave are discussed: Salby $(1981 \mathrm{a}, \mathrm{b})$ proposes that the quasi-2-day wave is a resonant amplification of the antisymmetric (3,3)-normal mode. Plumb (1983), however, suggests that the wave appears due to baroclinic instability near the summer stratospheric wind jet. The climatology of the quasi-2-day wave at Collm was described in detail by Jacobi et al. (1997c), who also pointed out that an influence of the 11-year solar cycle on its amplitude could be seen.

In the following, mesopause wind data measured at the Collm Observatory of the University of Leipzig are investigated with respect to a possible solar cycle dependence. The investigation will for the most part relate only to the zonal prevailing wind, being the parameter that in the past has been found to be most 
reliably influenced by solar variability (Jacobi et al., 1997a,b), and the quasi-2-day wave which also seems to be influenced by the solar cycle due to their connection to the vertical gradient of the prevailing wind.

\section{Description of measurements and data analysis}

The wind field of the upper mesopause region has been continually observed by daily D1 radio wind measurements in the LF range since 1959, using the ionospherically reflected sky wave of three commercial radio transmitters on 177,225 and $270 \mathrm{kHz}$. The measurements are carried out according to the closely-spaced receiver technique. A modified form of the similar-fade method has been used to interpret the wind measurements automatically since 1973 (Kürschner, 1975), and half-hourly mean values of the horizontal wind components are calculated for each of the three measuring paths. Monthly means of the half-hourly wind values are constructed. Since in summer during the day the absorption of the sky wave is too strong, the daily measuring period is then restricted to night and twilight.

Since the measurements are inhomogeneously distributed in time, a multiple regression analysis is used to determine the monthly prevailing wind and the semidiurnal tidal wind components using the half-hourly mean values of the measured zonal and meridional wind components. The spectral selectivity of the separation of prevailing and tidal wind is improved through fitting the measured monthly means of the half-hourly wind values for the two horizontal wind components as a vector, assuming clockwise circularly polarized tidal wind components (Kürschner, 1991):

$v_{z}=v_{o z}+b \bullet \sin (\omega t)+c \bullet \cos (\omega t)$,

$v_{m}=v_{\text {om }}+b \bullet \cos (\omega t)-c \bullet \sin (\omega t)$,

with $\omega=2 \pi / 12 \mathrm{~h}$, where $v_{z}$ and $v_{m}$ are the zonal and meridional monthly mean wind components, respectively, and $v_{o m}$ and $v_{o z}$ are the components of the horizontal prevailing wind. The semidiurnal phase $\left(T_{2 z}\right)$ and amplitude $\left(v_{2 z}\right)$ can be calculated from the coefficients $b$ and $c$, which along with the prevailing wind values are determined by a least-squares fit. The uncertainty of the monthly mean prevailing wind values amounts to $5 \mathrm{~m} \mathrm{~s}^{-1}$, which is mostly due to the variability of the prevailing wind on time-scales of less than 1 month. This is especially the case during spring and autumn, but also in winter due to rapid wind field transitions during stratospheric warmings (e.g. Schminder and Kürschner, 1981a,b, 1984). In summer, the variability of the prevailing wind is smaller, but then the vertical gradients are larger (about $2 \mathrm{~m} \mathrm{~s}^{-1} \mathrm{~km}^{-1}$ on a long-term average), which leads to an additional statistical uncertainty due to changes of the reflection height.

The diurnal tidal components are not taken into account here, because the daily, quasi-regularly distributed data gaps would lead to a large error in their calculation. Thus an additional error of the prevailing wind can occur when only night-time measurements are performed. At mid-latitudes the diurnal tide generally is a less dominant feature than the semidiurnal tide (e.g. Manson et al., 1989), although this is not necessarily the case in early summer. Estimates of the diurnal tide near $95 \mathrm{~km}$ can also be obtained from the Collm measurements [but using the original half-hourly wind values for a regression analysis with a modified form of Eq. (1) with height-dependent coefficients], and it was found from analyses in the past that in most of the months the diurnal tidal amplitude is much smaller than the semidiurnal one, although in spring and early summer they are of the same order of magnitude (Jacobi et al., 1997b) and thus its influence on the measurements should be kept in mind. To estimate the influence of neglecting the diurnal tide in Eq. (1), calculations were performed using an extended form of Eq. (1) that includes the diurnal tide. These calculations led to prevailing wind values that differed from those calculated using Eq. (1) by less than $4 \mathrm{~m} \mathrm{~s}^{-1}$ in each month of the year. However, one has to keep in mind that the diurnal tide in the case of the Collm measurements may lead to a bias in the calculation of the prevailing wind values, which is dependent on the tidal amplitude and phase. As this investigation aims at the interannual variability of the prevailing wind, this would mean that in some cases one cannot clearly distinguish between long-term variations of the prevailing wind and those of the semidiurnal tidal amplitude and phase. However, as will be shown in the following, the solar cycle variability of the prevailing wind amounts to about $10 \mathrm{~m} \mathrm{~s}^{-1}$, which is much larger than a possible influence by the diurnal tide, and thus, although some small tidal effect on the results is conceivable, this does not affect the results qualitatively.

Since September 1982 the reflection height $h$ has been measured on $177 \mathrm{kHz}$, using travel-time differences of corresponding modulation bursts between the ground wave and the reflected sky wave in the $1.8 \mathrm{kHz}$ modulation range (Kürschner et al., 1987). To avoid apparent wind variations due to reflection height variations in the presence of vertical gradients of the mean wind, only these times of day are used for the regression analysis given by Eq. (1), when the long-term mean reflection height is found to vary only slightly around the mean height of about $95 \mathrm{~km}$ (e.g. Jacobi et al., 1998).

\section{Results of monthly mean winds}

In Fig. 1 time series of the winter (December-February) and summer (June-August) mean zonal prevailing wind are shown. In the upper panel the 13-monthly mean sunspot number $R$ is shown. Only those data that have been obtained automatically since 1973 are used here to avoid possible artifacts due to the analysis by hand that was performed before that year. Regarding the winter time series of $v_{o z}$, some variability on a time-scale of 2-5 years can be seen. Additionally, Jacobi et al. (1996) found a weak dependence of the winter zonal prevailing wind on the equatorial QBO, but a connection between 


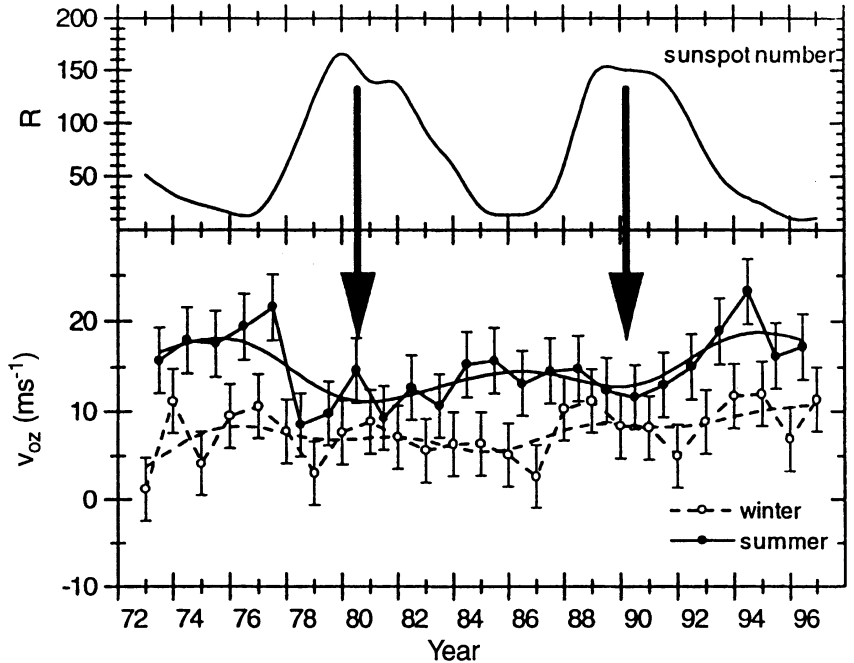

Fig. 1. Time series of winter (December-February) and summer (June-August) mean values of the Collm zonal prevailing wind $v_{o z}$ near $95 \mathrm{~km}$. In the upper panel the 13-monthly smoothed sunspot number $R$ is added (after Jacobi et al., 1997a, updated)

QBO, solar activity and winter mid-latitude circulation, as was found for the stratosphere (e.g. Labitzke and Loon, 1992, 1996), cannot be seen from the Collm measurements. This is probably due to the strongly variable reaction of the mesopause circulation to sudden stratospheric warmings. A solar effect on $v_{o z}$ in winter is not inferable from Fig. 1. However, in summer there is some evidence of a negative solar cycle dependence of $v_{o z}$. This is indicated by the two arrows in Fig. 1 that point to relative minimum values of the smoothed summer zonal prevailing wind. The correlation coefficient between $R$ and $v_{o z}$ in summer (using June-August means) is $r=0.65$, with $99 \%$ significance (t-test).

It can be seen from Fig. 1 that the long-term variability of the wind parameters is different for summer and winter. To take this into account, the time series of the zonal prevailing wind $v_{o z, i}$ in each month of the year are investigated with respect to a long-term trend and a solar cycle dependence using a multiple regression analysis according to

$v_{o z, i}=v_{x, i}+\Delta_{t, i} \bullet y r+\Delta_{R, i} \bullet R$,

where $y r$ is the time, counted in years, and $R$ is the 13monthly smoothed sunspot number, which is strongly correlated to the 10.7 solar radio flux (e.g. Rishbeth and Edwards, 1989) and can thus be taken as an indicator for solar activity. The parameters $v_{x, i}, \Delta_{t, i}$ and $\Delta_{R, i}$ are obtained by least-squares fit. The latter two represent the change in the zonal prevailing wind per year (i.e. the long-term trend) and the change in $v_{o z}$ per sunspot number (or the solar cycle dependence, respectively), while $v_{x}$ is a base value that is not of interest here, since it depends on the starting date of the time series.

The results for each month are shown in Fig. 2. The long-term trend is positive in most of the months, but it is relatively weak. It is interesting that this trend is different to the negative one reported by Bremer et al. (1997, their Figs. 4 and 7), and this shows that there is

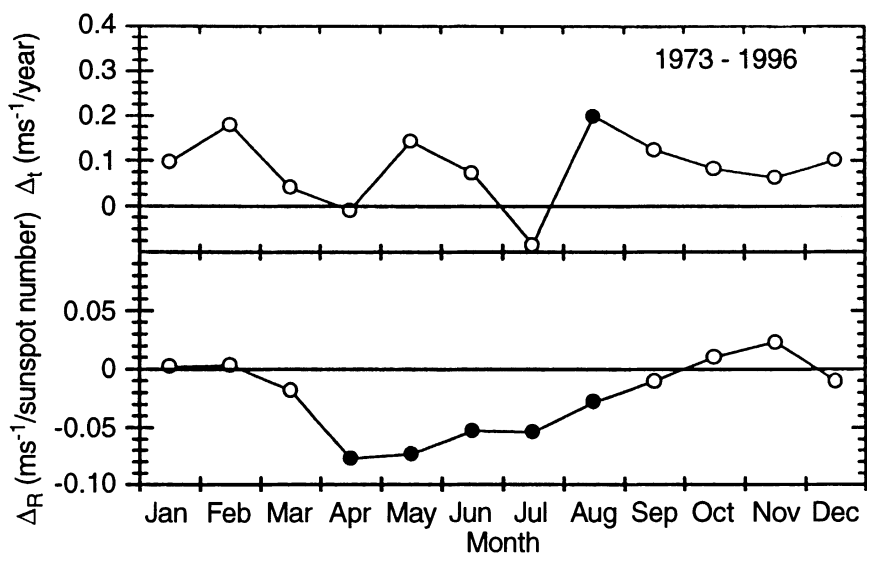

Fig. 2. Coefficients $\Delta_{t}$ (trend) and $\Delta_{R}$ (solar cycle dependence) for the zonal prevailing wind, calculated using Eq. (2) for each month. Solid symbols denote significance on the 95\%-level (after Jacobi et al., 1997a, updated)

obviously a variation in the mean wind at a time-scale of more than two decades, since the trend detected by Bremer et al. (1997) is for the most part due to the stronger westerlies in the 1960s and early 1970s.

The solar cycle dependence is shown in the lower panel of Fig. 2. In winter no significant influence of the solar cycle on the zonal prevailing wind is found. This coincides with numerical results of Arnold and Robinson (1998), who found a strong solar cycle dependence of the mesospheric wind, but this effect was strongly decreasing above about $80 \mathrm{~km}$. From Fig. 2 some of the results from literature cannot be confirmed (e.g. Sprenger and Schminder, 1969; Portnyagin et al., 1977), so that it may be concluded that the apparent solar cycle dependence that was found for certain periods is due to other effects of non-solar origin. Considering, for example, the results of Bremer et al. (1997, their Fig. 3) for D1 (1964-1994) and D2 (1976-1994) measurements, one can see different results for January and February, so that the most part of the solar cycle effect of the D1 measurements is obviously an effect contributed by the first years of measurements, and so it is not surprising that in this study, where only data since 1973 are used, no solar cycle effect on $v_{o z}$ is found in winter.

Thus the most striking point in Fig. 2 is the negative solar cycle dependence of the zonal prevailing wind in spring and summer that has already been found by other authors (e.g. Bremer et al., 1997; Jacobi et al., 1997a,b). From their analyses, also using Collm data, the same order of magnitude was obtained for the solar effect, and this is also the case for the analysis of Saskatoon data made by Namboothiri et al. (1993a).

Considering the results from Collm, however, one has to take into account that the wind values used in Eq. (2) here are calculated without explicitly taking the reflection height into account, and therefore a solar cycle dependence of the reflection height would lead to an apparent solar effect on the measured zonal prevailing wind. For example, Entzian (1967) showed that during solar maximum the height of a fixed electron density is lower during solar maximum than it is during solar 


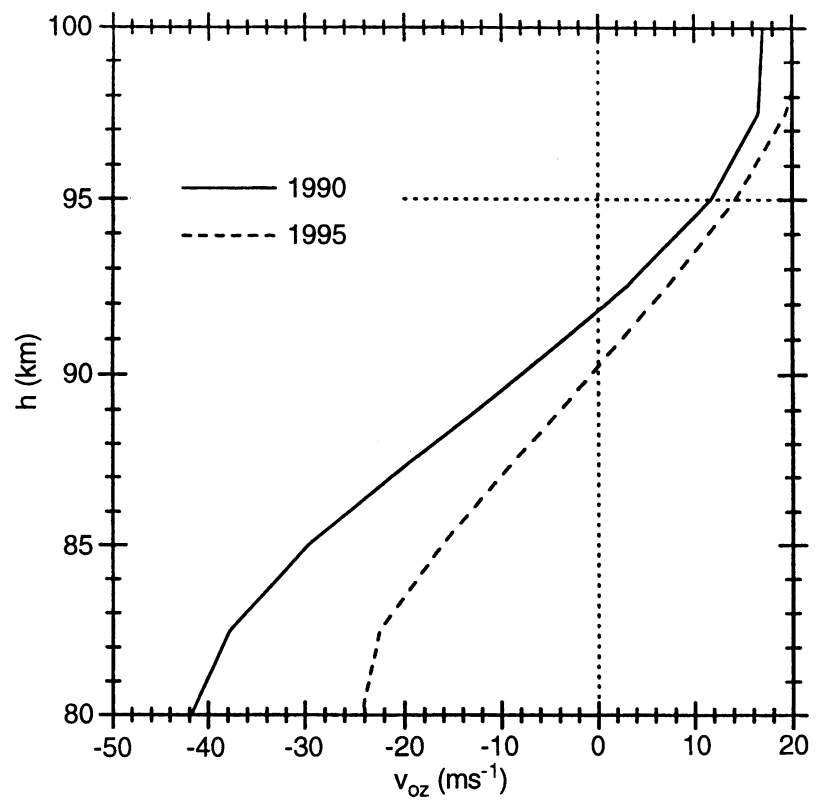

Fig. 3. June-August mean profiles of mesosphere/lower thermosphere zonal prevailing winds for high $(1990, R=151)$ and low (1995, $R=15$ ) solar activity. The data are taken from joint analyses of Collm LF D1 and Juliusruh MF radar data (Schminder et al., 1994, 1997b)

minimum, and Cossart (1984) and Cossart and Taubenheim (1987) showed from indirect LF phase-height measurements that there is a difference of about $1 \mathrm{~km}$ in the reflection height between high and low solar activity. Using medium-frequency height measurements, Namboothiri et al. (1993b) found even larger differences for virtual reflection heights. Since at Collm the reflection height has also been measured since 1983, the solar influence on the reflection height can be estimated. Using yearly means of mean night-time reflection heights it is found that the mean height for years with high solar activity $(R>100)$ is $94.5 \pm 0.4 \mathrm{~km}$, while it is $95.6 \pm 0.9 \mathrm{~km}$ for the years of low solar activity $(R<50)$. The uncertainties given here are taken from the standard deviation of the mean annual heights. Since the data-base consists only of 4 and 7 years for high and low solar activity, respectively, this result is not statistically significant, but as it confirms the results in the literature, one may conclude that a mean night-time height difference of about $1-1.5 \mathrm{~km}$ is a reasonable estimate for the solar influence on the reflection height. The largest vertical gradients of the zonal prevailing wind are found in summer, when on a long-term average values of about $2 \mathrm{~m} \mathrm{~s}^{-1} \mathrm{~km}^{-1}$ are found (e.g. Schminder et al., 1997a, Jacobi et al., 1997b). Thus an apparent solar cycle wind variation of up to $3 \mathrm{~m} \mathrm{~s}^{-1}$ due to height variations has to be taken into account, and has to be subtracted from the values found from the analysis according to Eq. (2), since in summer at lower heights the zonal westerly winds are smaller and thus the solar cycle dependence of $v_{o z}$ due to height variations is negative as well. From Figs. 1 and 2 one can see that in summer the zonal wind difference between solar maximum and solar minimum amounts to about $8 \mathrm{~m} \mathrm{~s}^{-1}$, so one may conclude that although the height variability may possibly contribute up to nearly $40 \%$ to a solar cycle dependence of the measured $v_{o z}$, it is not responsible for the whole effect, and a real wind variation has to be present. Additionally, from analyses of the years 1983 through 1995 that included the measured reflection heights at Collm and therefore excluded height effects (Jacobi et al., 1997b, their Fig. 7), wind variations within a solar cycle were found that are of the same order of magnitude as those shown in Fig. 2, and although the analysis of trends from a data base which is not much longer than one solar cycle has to be interpreted with care, the coincidence between the results presented here and those of Jacobi et al. (1997b) gives some hint that the coefficients shown in Fig. 2 are for the most part due to real wind variations.

In summer the westerly mesopause jet is situated at about $95 \mathrm{~km}$ height. However, the interannual variability of this jet reflects the behaviour of the mesosphere below as well. To visualise this, in Fig. 3 shows summer mean profiles of the zonal prevailing wind, calculated from joint analyses (Schminder et al., 1994, 1997b) of Collm D1 LF and Juliusruh medium-frequency (MF) radar data. The MF radar data were provided by the Institute of Atmospheric Physics at Kühlungsborn, Germany. It can be seen that the stronger westerly winds in the mesopause region in 1995 compared to 1990 are connected with weaker easterlies in the mesosphere below. Furthermore, the interannual variations appear to be stronger in the mesosphere, which can already be seen from the results of Schminder et al. (1997b, their Fig. 2). This gives a hint of a stronger vertical zonal prevailing wind gradient during solar maximum. The interannual variability of the gradient itself can be seen from the original half-hourly Collm wind data of the years 1983-1996, using a modified form of Eq. (1) with height-dependent coefficients:

$v_{z}=\sum_{k=0}^{2} h^{k} a_{0 k, z}+\sum_{k=0}^{2} b_{k} h^{k} \sin \omega t+\sum_{k=0}^{2} c_{k} h^{k} \cos \omega t$,
$v_{m}=\sum_{k=0}^{2} h^{k} a_{0 k, m}+\sum_{k=0}^{2} b_{k} h^{k} \cos \omega t-\sum_{k=0}^{2} c_{k} h^{k} \sin \omega t$,

again with $\omega=2 \pi / 12 \mathrm{~h}$. Time-series of the June-August mean vertical zonal prevailing wind gradients, calculated for a height of $90 \mathrm{~km}$, are shown in Fig. 4. The 13monthly smoothed sunspot number is also added. Besides a long-term trend of the vertical gradient, a solar cycle dependence is also indicated. This is well visible in Fig. 5, showing the detrended summer vertical zonal wind gradients in dependence of the sunspot number $R$. The correlation is significant at the $95 \%$-level (t-test).

The effect of the solar cycle on the meridional prevailing wind $v_{o m}$, the semidiurnal tidal amplitude $v_{2 z}$, and the semidiurnal tidal phase $T_{2 z}$ is presented in Fig. 6, showing the coefficient $\Delta_{R}$ as in Eq. (2) but using monthly analyses of the respective wind parameter as indicated in the legend. A weak positive solar cycle dependence of the meridional prevailing wind in winter is visible, so that during solar maximum the southerly 


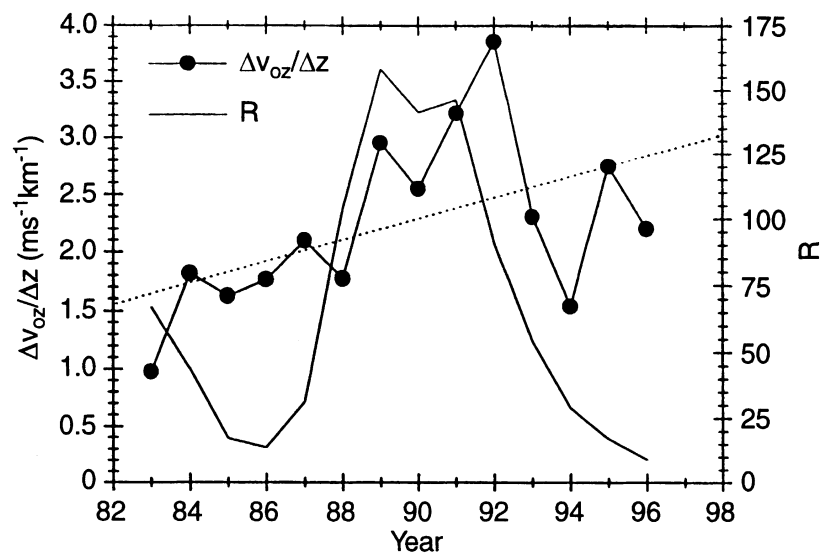

Fig. 4. Time series of Collm summer (June-August) mean vertical gradients of the mesopause zonal prevailing wind at $90 \mathrm{~km}$. The dotted line shows the linear trend. The 13-monthly smoothed sunspot number $R$ is added

winds above $90-95 \mathrm{~km}$ are somewhat weaker, although this correlation is not statistically significant except in March and October, when rapid changes in the mesopause region wind field usually occur (e.g. Schminder et al., 1997a). So this may hint to a possible longer duration of the winter circulation in solar maximum, although analyses of the day-to-day variability of the wind parameters during March and October (not shown here) have so far not led to clear conclusions, and the interannual variability of the spring and autumn transition should thus be left to future investigation.

The amplitude of the semidiurnal tide in the most part of the year also shows no significant solar cycle effect, except in April, but during this month rapid changes of the tidal wind field also occur, and so any analysis of this month using monthly means should be regarded with

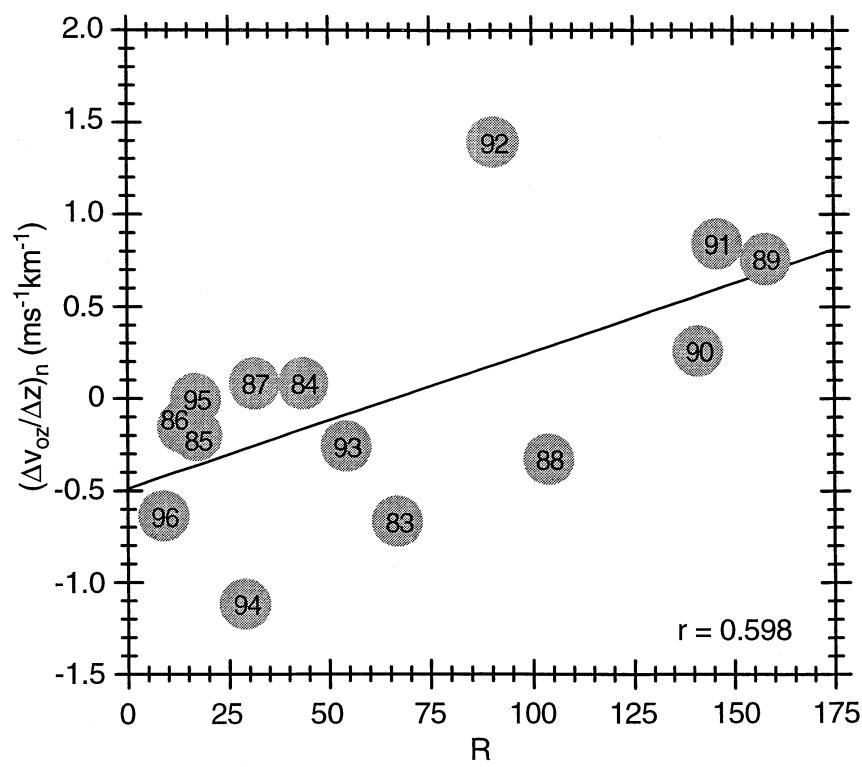

Fig. 5. Detrended Collm mean summer (June-August) vertical gradient of the zonal prevailing wind at $90 \mathrm{~km}$ height in dependence on the 13-monthly smoothed sunspot number $R$. The correlation coefficient $r$ is also given

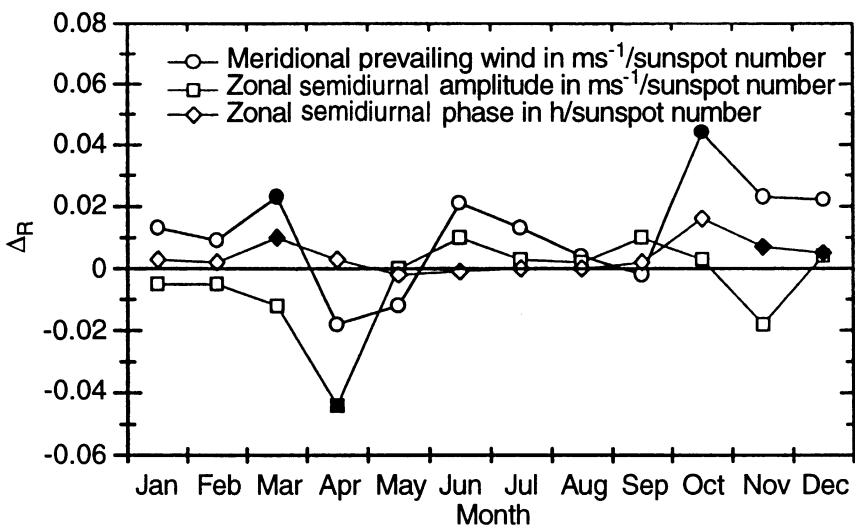

Fig. 6. Coefficient $\Delta_{R}$ (solar cycle dependence) of the meridional prevailing wind, the zonal semidiurnal tidal amplitude and the zonal semidiurnal phase, calculated using Eq. (2) for each month. Solid symbols denote significance on the $95 \%$-level. The coefficients for the meridional prevailing wind and the semidiurnal tidal amplitudes are updates after Jacobi et al. (1997a)

care. The phase of the semidiurnal tide in winter is positively correlated with the solar cycle, so that the maximum winds are found at later times in years of high solar activity. It has been found from the analysis of winter winds that stratospheric warmings have some influence upon the semidiurnal tidal phase (e.g. Schminder and Kürschner, 1981a,b, 1990), so that, considering the influence of the solar cycle upon major stratwarm events (e.g. Labitzke and Loon, 1992, 1996), one may speculate about a solar effect on the semidiurnal tide due to winter stratospheric variability. However, the effect of stratwarm on the semidiurnal tide is small compared to the one upon the prevailing wind (e.g. Schminder and Kürschner, 1990), and the influence may even vary from case to case (Schminder and Kürschner, 1981b). Furthermore, the large day-to-day variability of the wind field in winter leads to uncertainties of the estimated tidal phases, so that it is doubtful whether monthly analyses are suitable for the investigation of the long-term variability of the tidal phase, and more detailed analyses based upon shorter periods should preferably be used for such studies. In addition, similar analyses as in Fig. 6, but using the period from 1980 through 1996 only, do not show any significant solar cycle effect upon $T_{2 z}$, so that the results shown in Fig. 6 are mainly due to the variability of the tides in the 1970s, and this may be of non-solar origin. However, a possible solar cycle effect on the semidiurnal tide cannot be excluded. As Arnold and Robinson (1998) showed, the mesosphere below about $80 \mathrm{~km}$ altitude in winter is strongly influenced by solar variability, and this may lead to changes in the tidal propagation during a solar cycle.

\section{Interannual variability of the quasi-2-day wave}

The quasi-2-day wave at Collm is calculated from the original half-hourly wind and reflection height values using an extended form of Eq. (1), but with linearly height-dependent coefficients: 


$$
\begin{aligned}
v_{z}= & \sum_{k=0}^{1} h^{k} a_{0 k, z}+\sum_{j=1}^{2} \\
& \left(\sum_{k=0}^{1} b_{j k, z} h^{k} \sin \omega_{j} t+\sum_{k=0}^{1} c_{j k, z} h^{k} \cos \omega_{j} t\right) \\
v_{m}= & \sum_{k=0}^{1} h^{k} a_{0 k, m}+\sum_{j=1}^{2} \\
& \left(\sum_{k=0}^{1} b_{j k, m} h^{k} \sin \omega_{j} t+\sum_{k=0}^{1} c_{j k, m} h^{k} \cos \omega_{j} t\right)
\end{aligned}
$$

where two oscillations are taken into account. The frequencies included are $\omega_{1}=2 \pi / 12 \mathrm{~h}$ for the semidiurnal tide and $\omega_{2}=2 \pi / 48 \mathrm{~h}$ for the quasi-2-day wave. Since $P$ is generally found to be not exactly $48 \mathrm{~h}$ and therefore is not known a priori, Jacobi et al. (1997c) calculated a regression analysis according to Eq. (3) for each period $P$ in the range $43 \mathrm{~h}<P<58 \mathrm{~h}$ and used the one that provided the best fit between measured and calculated data. They found that during the maximum of the events the period is smaller than $48 \mathrm{~h}$, while before and after that time the periods can be longer. This was also found by Thayaparan et al. (1997a,b) for the years 1993 and 1994. However, since during a 2-day wave event the period values change from large ones to smaller ones and back to long periods, an analysis that includes only the 48 -h period also leads to reasonable results in the vicinity of the amplitude maximum. The amplitude components of the quasi-2-day wave were calculated according to:

$$
\begin{aligned}
& V_{48, z}(h)=\sqrt{\left(\sum_{k=0}^{1} b_{2 k, z} h^{k}\right)^{2}+\left(\sum_{k=0}^{1} c_{2 k, z} h^{k}\right)^{2}}, \\
& V_{48, m}(h)=\sqrt{\left(\sum_{k=0}^{1} b_{2 k, m} h^{k}\right)^{2}+\left(\sum_{k=0}^{1} c_{2 k, m} h^{k}\right)^{2}} .
\end{aligned}
$$

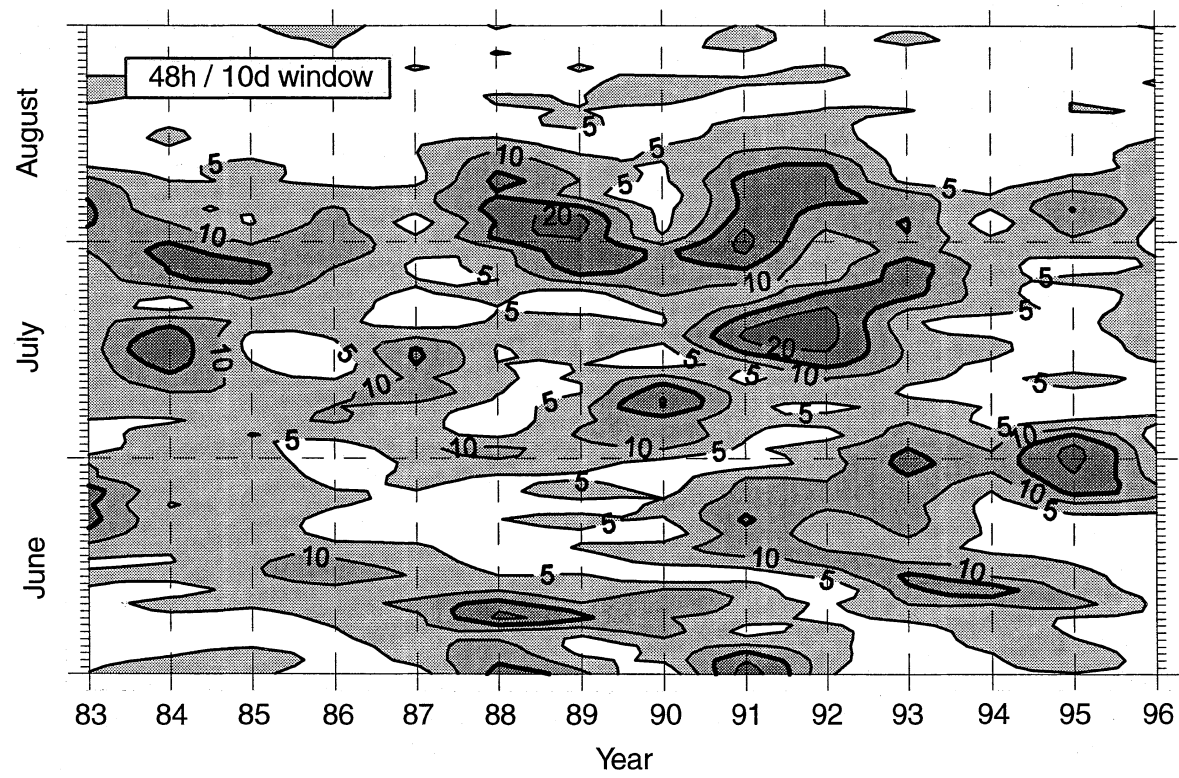

Each analysis was made using a 10-day data window. To give an impression of the interannual variability of the 2-day oscillation, the zonal amplitudes at $95 \mathrm{~km}$, a height near the maximum measuring density, are shown in Fig. 7. It can be seen that wave activity is quite variable, but there is a tendency for enhanced activity in the years 1988-1992, thus a dependence of the 2-day amplitude on the solar activity is suggested. Therefore, in Fig. 8 the monthly mean 2-day amplitude

$V_{48}=\sqrt{V_{48, z}^{2}+V_{48, m}^{2}}$

is shown in dependence on the sunspot number $R$ for the months June-August. In the lowermost panel the mean summer amplitudes are presented. It can be seen that the 2-day wave amplitude is positively correlated with the solar activity, as already suggested by Jacobi et al. (1997c) for the period 1983-1995. Obviously this correlation is due to the fact that the quasi-2-day wave is positively dependent on the mean mesospheric zonal prevailing vertical wind gradient, so that the excitation of the wave is enhanced when the mesospheric easterly jet is stronger, or, in turn, the upper mesopause westerlies are weaker. Since in summer the vertical zonal prevailing wind gradient is positively correlated with the solar activity, this leads to the positive correlation of $V_{48}$ and $R$. The correlation coefficients are shown in the respective panels of Fig. 8. However, from Fig. 8 it can be seen that only in August is the correlation relatively strong and therefore statistically significant at the 95\% level (t-test, $r>0.55$ ). This could be due to the fact that the quasi-2-day wave is a very regular phenomenon and appears nearly every summer, and additionally that the events are more or less irregularly distributed, as can be seen from Fig. 7. This means that during solar maximum only an enhanced probability for the appearance of 2-day wave events is found. Since in July this probability is large in any case, the enhancement during solar maximum is not significant for July, while in August, when during solar minimum the
Fig. 7. Zonal amplitude $v_{48, z}$ of the 2-day wave in June-August 1983-1996. The values are calculated from running 10-day data windows with a step rate of 1 day 


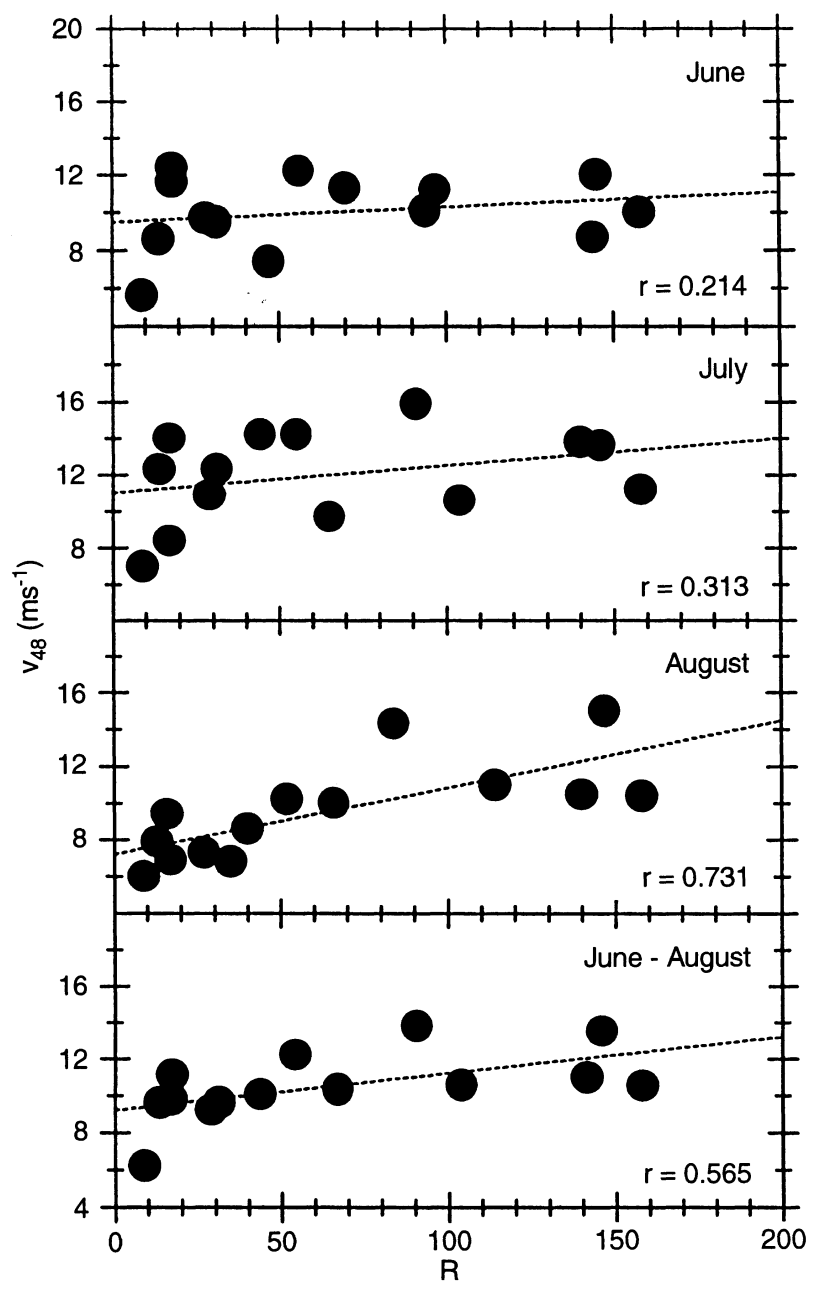

Fig. 8. Correlation between the monthly mean 2-day amplitude $V_{48}$ and the 13-monthly smoothed sunspot number $R$ for the months June-August, from Collm measurements of the years 1983-1996. The respective correlation coefficients $r$ are also given

events appear more rarely, the enhanced probability for the appearance of the events can be seen more clearly.

However, as this result, like that for the vertical gradient of the zonal prevailing wind, is taken from a data base of only 14 years and bearing in mind the longterm oscillations of the semidiurnal tide and the possibility that such oscillations may also be present in the signal of the quasi-2-day wave, one has to be careful in interpreting the results presented here. In addition, the correlation between quasi-2-day wave and solar activity is statistically significant only in one month, so that the results concerning the solar cycle dependence of the quasi-2-day wave should be considered with some care, although they fit into the general picture and are therefore a further hint of solar effects on the upper middle atmosphere dynamics.

\section{Conclusions}

From the long-term time series of mesopause region winds measured at Collm, possible effects of the solar variability on upper middle atmospheric dynamical properties can be inferred. It was found that the spring and summer zonal prevailing wind is negatively dependent on the solar activity, meaning the westerly winds are weaker during solar maximum. As can be seen from Fig. 3, this relation seems to be due to a forcing from below, which is indicated by joint analyses of Juliusruh mesospheric and Collm mesopause region wind data from 1990-1996 (Schminder et al., 1994, 1997b). This also suggests a possible positive correlation of the strength of the summer mesospheric easterlies with the solar cycle. Although Juliusruh MF radar data are only available for a period of less than one solar cycle, the data available do support this suggestion (Schminder et al., 1997b). Additionally, regarding the vertical zonal prevailing wind gradients from 14 years of Collm measurements, this suggestion is again supported, since the gradients are positively correlated with the solar activity. However, as found, for example, by Jacobi et al. (1997a), the mesosphere/lower thermosphere circulation is variable on partially very long time-scales and the detection of any dependence may lead to incorrect results if the time-series used is shorter than about two decades. This means, considering all the measurements regarded here, that a forcing of the solar cycle dependence of the mesopause region mean circulation from below is indeed strongly suggested, but for a direct proof still longer time series of measurements may be necessary.

The quasi-2-day wave activity, however, also fits into this picture. The mean summer amplitude - which is actually a mixture of maximum amplitudes and probability of appearance - is enhanced during solar maximum, and this can be explained by the stronger vertical wind gradients at this time. Even if the data base from which the solar activity quasi-2-day wave correlation is inferred is rather short compared to the timescales of periodicities present in the upper mesosphere/ lower thermosphere dynamics, this again indicates that the mesospheric circulation is dependent on the solar activity as described in the previous paragraph.

Thus the solar cycle dependence of the mesopause region mean circulation and quasi-2-day wave would be a result of a solar cycle dependence of at least the lower thermosphere and the mesosphere. Therefore the mesopause region measurements might be useful for monitoring the long-term variability and solar cycle dependences of the entire middle atmosphere.

Acknowledgements. This research was supported by the Deutsche Forschungsgemeinschaft under contract Schm 981/2-2. I am very grateful to Dr. R. Schminder and Dr. D. Kürschner, Collm, for providing the Collm wind data and for many helpful discussions. The MF radar data were provided by Dr. W. Singer and Dr. P. Hoffmann, Institute of Atmospheric Physics, Kühlungsborn.

Topical Editor F. Vial thanks T. Thayaparan and another referee for their help in evaluating this paper.

\section{References}

Arnold, N. F., and T. R. Robinson, Solar cycle changes to planetary wave propagation and their influence on the middle atmosphere circulation, Ann. Geophysicae, 16, 69-76, 1998. 
Babadshanov, P. B., B. V. Kalchenko, B. L. Kashcheyev, and V. V Fedynsky, Winds in the equatorial lower thermosphere (in Russian), Proc. Acad. Sci. USSR, 208, 1334-1337, 1973.

Bremer, J., R. Schminder, K. M. Greisiger, P. Hoffmann, D. Kürschner, and W. Singer, Solar cycle dependence and longterm trends in the wind field of the mesosphere/lower thermosphere, J. Atmos. Solar-Terr. Phys., 59, 497-509, 1997.

Cossart, G. von Influence of the solar cycle upon the upper mesosphere. Gerlands Beitr. Geophys, 5, 329-338, 1984.

Cossart, G. von and J. Taubenheim, Solar cycle and long-period variations of mesospheric temperatures, J. Atmos. Terr. Phys., 49, 303-307, 1987

Dartt, D., G. Nastrom, and A. Belmont, Seasonal and solar cycle wind variations, 80-100 km, J. Atmos. Terr. Phys., 45, 707-718, 1983.

D'Yachenko, V. A., I. A. Lysenko, and Yu. I. Portnyagin, Longterm periodicities in lower thermospheric wind variations, $J$. Atmos. Terr. Phys., 48, 1117-1119, 1986.

Entzian, G., Der Sonnenfleckenzyklus in der Elektronenkonzentration der D-Region, Kleinheubacher Ber., 12, 309-313, 1967.

Fraser, G. J., Long-term variations in the mid-latitude southern hemisphere mesospheric winds, Adv. Space Res., 10(10), 247250, 1990.

Fraser, G. J., R. A. Vincent, A. H. Manson, C. E. Meek, and R. R. Clark, Inter-annual variability of tides in the mesosphere and lower thermosphere, J. Atmos. Terr. Phys., 51, 555-567, 1989.

Gregory, J. B., C. E. Meek, and A. H. Manson, Mean zonal and meridional wind profiles for the mesosphere and lower thermosphere at $52^{\circ} \mathrm{N}, \mathrm{L}=4.4$, during solar maximum. Atmos. Ocean, 19, 24-34, 1981.

Greisiger, K. M., R. Schminder, and D. Kürschner, Long-period variations of wind parameters in the mesopause region and the solar cycle dependence, J. Atmos. Terr. Phys., 49, 281-285, 1987.

Harris, T. J., A long-term study of the quasi-two-day wave in the middle atmosphere, J. Atmos. Terr. Phys., 56, 569-579, 1994.

Jacobi, C., R. Schminder, and D. Kürschner, On the influence of the stratospheric quasi-biennial oscillation on the mesopause zonal wind over Central Europe, Meteorol. Z., N.F., 5, 318-323, 1996.

Jacobi, C., R. Schminder, D. Kürschner, J. Bremer, K. M. Greisiger, P. Hoffmann, and W. Singer, Long-term trends in the mesopause wind field obtained from D1 LF wind measurements at Collm, Germany, Adv. Space Res., 20, 2085-2088, 1997a.

Jacobi, C., R. Schminder, and D. Kürschner, Measurements of mesopause region winds over Central Europe from 1983 through 1995 at Collm, Germany. Contrib. Atmos. Phys., 70, 189-200, 1997b.

Jacobi, C., R. Schminder, and D. Kürschner, The quasi two-day wave as seen from D1 LF wind measurements over Central Europe $\left(52^{\circ} \mathrm{N}, 15^{\circ} \mathrm{E}\right)$ at Collm, J. Atmos. Solar-Terr. Phys., 59, 1277-1286, 1997c.

Jacobi, C., R. Schminder, and D. Kürschner, Planetary wave activity obtained from long-term (2-18 days) variations of mesopause region winds over Central Europe $\left(52^{\circ} \mathrm{N}, 15^{\circ} \mathrm{E}\right), \mathrm{J}$. Atmos. Solar-Terr. Phys., 60, 81-93, 1998.

Kürschner, D., Konzeption und Realisierung eines vollautomatischen Registriersystems zur Durchführung von nach der D1Methode angelegten Routinebeobachtungen ionosphärischer Driftparameter am Observatorium Collm, Z. Meteorol., 25, 218-221, 1975.

Kürschner, D., Ein Beitrag zur statistischen Analyse hochatmosphärischer Winddaten aus bodengebundenen Messungen, Z. Meteorol., 41, 262-266, 1991.

Kürschner, D., R. Schminder, W. Singer, and J. Bremer, Ein neues Verfahren zur Realisierung absoluter Reflexionshöhenmessungen an Raumwellen amplitudenmodulierter Rundfunksender bei Schrägeinfall im Langwellenbereich als Hilfsmittel zur Ableitung von Windprofilen in der oberen Mesopausenregion, Z. Meteorol., 37, 322-332, 1987.

Labitzke, K., and $\mathbf{H}$. van Loon, On the association between the QBO and the extratropical stratosphere, J. Atmos. Terr. Phys., 54, 1453-1463, 1992.
Labitzke, K., and H. van Loon, On the stratosphere, the QBO, and the sun: the winter of 1995-1996, Meteorol Z., N.F., 5, 166-169, 1996.

Manson, A. H., C. E. Meek, H. Teitelbaum, F. Vial, R. Schminder, D. Kürschner, M. J. Smith, G. J. Fraser, and R. R. Clark, Climatologies of semi-diurnal and diurnal tides in the middle atmosphere $(70-110 \mathrm{~km})$ at middle latitudes $\left(40-55^{\circ}\right), \mathrm{J}$. Atmos. Terr. Phys., 51, 579-593, 1989.

Meek, C. E., A. H. Manson, S. J. Franke, W. Singer, P. Hoffmann, R. R. Clark, T. Tsuda, T. Nakaura, M. Tsutsumi, M. Hagan, D. C. Fritts, J. Isler, and Yu. I. Portnyagin, Global study of northern hemisphere quasi-2-day events in recent summers near $90 \mathrm{~km}$ altitude, J. Atmos. Terr. Phys., 58, 1401-1411, 1996.

Muller, H. G., Long-period wind oscillations, Phil. Trans. R. Soc., A272, 585-598, 1972.

Muller, H. G., and L. Nelson, A travelling quasi 2-day wave in the meteor region, J. Atmos. Terr. Phys., 40, 761-766, 1978.

Namboothiri, S. P., A. H. Manson, and C. E. Meek, Variations of mean winds and tides in the upper middle atmosphere over a solar cycle, Saskatoon, Canada, $52^{\circ} \mathrm{N}, 107^{\circ} \mathrm{W}$, J. Atmos. Terr. Phys., 55, 1325-1334, 1993a.

Namboothiri, S. P., A. H. Manson, and C. E. Meek, E-region real heights and their implications for MF radar-derived wind and tidal climatologies, Radio Sci., 28, 187-202, 1993b.

Plumb, R. A., Baroclinic instability of the summer mesosphere: a mechanism for the quasi-two-day wave? J. Atmos. Sci., 40, 262270, 1983.

Poole, L. M. G., and T. J. Harris, The propagation of the mesospheric two-day wave in the southern hemisphere, $J$. Atmos. Terr. Phys., 57, 1661-1666, 1995.

Portnyagin, Yu. I., G. V. Kaidalov, K. M. Greisiger, and K. Sprenger, Zur Abhängigkeit der Windparameter der Mesopausenregion vom 11-jährigen Zyklus der Sonnenaktivität, Phys. Solariterr., 5, 91-96, 1977.

Rishbeth, H., and R. Edwards, The isobaric F2-layer, J. Atmos. Terr. Phys., 51, 321-338, 1989.

Rodgers, C.D., and A. J. Prata, Evidence for a travelling 2-day wave in the middle atmosphere, J. Geophys. Res., 86, 96619664, 1981.

Salby, M. L., Rossby normal modes in nonuniform background configurations. Part II: equinox and solstice conditions, $J$. Atmos. Sci., 38, 1827-1840, 1981a.

Salby, M. L., The 2-day wave in the middle atmosphere: observations and theory, J. Geophys. Res., 86, 9654-9660, 1981b.

Schminder, R., and D. Kürschner, Wind field anomalies in the upper mesopause region over Central Europe and the major stratospheric warming in February 1981, J. Atmos. Terr. Phys., 43, 735-736, 1981a.

Schminder, R., and D. Kürschner, Seasonal variations of the wind field of the upper mesopause region in 1979, Gerlands Beitr. Geophys., 90, 22-32, 1981b.

Schminder, R., and D. Kürschner, Wind-field change in the upper mesopause region over Central Europe during stratospheric warmings in February/March 1984 obtained from vertical wind profiles between 90 and $110 \mathrm{~km}$ altitude measured at the Collm Geophysical Observatory, J. Atmos. Terr. Phys., 46, 711-716, 1984.

Schminder, R., and D. Kürschner, Variability of tides especially during stratwarm, Adv. Space Res., 10(12), 141-151, 1990.

Schminder, R., W. Singer, D. Kürschner, P. Hoffmann, and D. Keuer, Permanent monitoring of the upper atmosphere wind field over Central Europe by a joint analysis of LF wind profiler and MF radar measurements at Collm and Juliusruh (Germany), Meteorol. Z., N.F., 3, 297-300, 1994.

Schminder, R., D. Kürschner, W. Singer, P. Hoffmann, D. Keuer, and $\mathbf{J}$. Bremer, Representative height-time cross-sections of the upper atmosphere wind field over Central Europe 1990-1996, J. Atmos. Terr. Phys., 59, 2177-2184, 1997a.

Schminder, R., C. Jacobi, D. Kürschner, P. Hoffmann, D. Keuer, and $\mathbf{W}$. Singer, The upper mesosphere and lower thermosphere 
C. Jacobi: On the solar cycle dependence of winds and planetary waves as seen from mid-latitude

wind field over Central Europe from 1994 through 1996 obtained from a joint analysis of LF windprofiler and MF radar measurements, Meteorol. Z., N.F., 6, 225-229, 1997b.

Sprenger, K., and R. Schminder, Solar cycle dependence of winds in the lower ionosphere, J. Atmos. Terr. Phys., 31, 217-221, 1969.

Thayaparan, T., W. K. Hocking, and J. MacDougall, Amplitude, phase, and period variations of the quasi 2-day wave in the mesosphere and lower thermosphere over London, Canada $\left(43^{\circ} \mathrm{N}, 81^{\circ} \mathrm{W}\right)$, during 1993 and 1994, J. Geophys. Res., 102, 9461-9478, 1997a.

Thayaparan, T., W. K. Hocking, J. MacDougall, A. H. Manson, and C. E. Meek, Simultaneous observations of the 2-day wave at London $\left(43^{\circ} \mathrm{N}, 81^{\circ} \mathrm{W}\right)$ and Saskatoon $\left(52^{\circ} \mathrm{N}, 107^{\circ} \mathrm{W}\right)$ near $91 \mathrm{~km}$ altitude during the two years of 1993 and 1994. Ann. Geophysicae, 15, 1324-1339, 1997b. 